\title{
TRAÇOS FENOMENOLÓGICOS NO PENSAMENTO JURÍDICO DE LUÍS CABRAL DE MONCADA
}

\author{
Ana Paula Loureiro de Sousa \\ Centro de Filosofa da UL \\ Universidade Lusófona
}

1. Luís Cabral de Moncada foi um dos precursores da fenomenologia em Portugal no âmbito da reflexão jusfilosófica. ${ }^{1}$ Tal pode ser verificado, de um modo informativo, nos escritos da Polémica $(1928-1929)^{2}$ e, de forma mais consistente e desenvolvida, nos seus estudos filosófico-jurídicos posteriores, nomeadamente em Valor e sentido da democracia (1930), «Prefácio» à tradução portuguesa de Filosofia do direito, de Gustav Radbruch (1933), Direito positivo e ciência do direito (1944), A caminho de um novo direito natural (1945), Será a jurisprudência uma ciência? (1947), Sobre epistemologia jurídica (1948), tal como em escritos de feição mais ontológico-metafísica, em particular no ensaio O problema do direito natural no pensamento contemporâneo (1949) e, mais tardiamente, em $O$ direito como objeto de conhecimento (1969).

\footnotetext{
${ }^{1}$ Luís Cabral de Moncada nasceu em Lisboa em 1888, fez os seus estudos no colégio dos Jesuitas de S. Fiel (1900 a 1906), licenciou-se na Faculdade de Direito de Coimbra (1906-1911), doutorou-se na mesma cidade, em 1918, ascendeu a professor catedrático em 1924, na secção de ciências histórico-jurídicas e em 1958 jubilou-se. Faleceu em Coimbra em 1974.

${ }^{2}$ Luís Cabral de Moncada teve um convite da Associação Académica de Coimbra, para comemorar a data do $10^{\circ}$ de dezembro. Apresenta a comunicação, "1940 Restauração do pensamento político português". Esse texto foi publicado em opúsculo e, posteriormente, inserido nos Estudos de história do direito. Ora, meio ano após essa conferência, Vitorino Nemésio escreve na revista Seara Nova, em maio de 1928, um artigo criticando Moncada e o teor da sua conferência. Moncada responde-lhe em junho desse ano na revista Nação Portuguesa. Começa a polémica entre Nemésio e Moncada que só termina quando António Sérgio intervém a favor de Nemésio. Nesta altura, em 1929, a polémica vai ser exclusiva entre Sérgio e Moncada.
} 
Os textos da Polémica, nascidos da discussão que Moncada teve com António Sérgio, versam sobre as relações epistemológicas entre o ser e o dever-ser, entre o ideal e o facto sensível, a política e a ciência, os meios e os fins. ${ }^{3}$ Neles já se encontram em gérmen as correntes modernas do pensamento germânico, como o neo-kantismo, a filosofia dos valores e a fenomenologia, bem como o contributo dessas correntes para a defesa de uma ética material dos valores e de uma ontologia pluralista. Apesar de não encontrarmos muitas referências nestes textos à fenomenologia, entrevemos alguma aproximação àquela corrente de pensamento nas seguintes ideias: em «Breve Esclarecimento de algumas Teses de Filosofia Política, Moral e da História», elucidando a noção de «realismo crítico», ou realismo integral, Moncada escreve uma nota, muito breve, sobre a fenomenologia admitindo-a "como um critério de verificação e de controle para todas as especulações nos domínios das ciências do espírito". ${ }^{4}$ Ainda neste texto, e em "Ideal e Facto Sensível», a respeito da conceção de sociedade, defende que viver pessoalmente é viver num horizonte comunitário no qual se realizam os projetos e fins espirituais que vão dando origem à cultura e à história, por isso a sociedade é dinâmica e aberta, constituindo-se a partir da relação com o outro, a lembrar-nos as palavras husserlianas, "a comunidade das pessoas como comunidade de vida pessoal num primeiro" é o "explícito ser-vivo-em-união com outrem no compreender intuitivo, do seu experienciar, da situação de vida e do seu agir". No que concerne à noção de consciência, também encontramos alguma afinidade com o pensamento fenomenológico, porquanto Moncada sustenta que a consciência não se pode definir como meramente psíquica, mas envolve um sentido transcendental. A consciência debruçando-se sobre o mundo numa atitude de "pura especulação" descobre a "imagem, a objetivação, alguma coisa que se exteriorizou [...] e se «precipitou» dos seus próprios dados imediatos". ${ }^{\prime}$ Neste sentido, aparece como uma cadeia ou conjunto de experiências vividas tendo cada uma delas a sua própria essência. Mais tarde, esta

${ }^{3}$ Os textos têm como tema: "O Ideal e Facto Sensível, Política e Ciência, Meios e Fins", março de 1929; "Método Científico, História, Política (Moral) e Tradição", abril de 1929; "Idealismo e Realismo - Fim de uma Polémica Inútil", julho de 1929; "Breve Esclarecimento de Algumas Teses de Filosofia Política, Moral e História”, novembro de 1929.

${ }^{4}$ Luís Cabral de Moncada, "Breve Esclarecimento de Algumas Teses de Filosofia Política, Moral e História". Nação Portuguıesa, tomo I, série VI, 2. fasc., n. ${ }^{\circ}$ 3, nov. de 1929, p. 180.

${ }^{5}$ Hua VI (A Crise das Ciências Europeias e a Fenomenologia Transcendental. Uma Introdução à Filosofia Fenomenológica), trad. de Diogo Falcão Ferrer. Lisboa: Centro de Filosofia da Universidade de Lisboa, 2008, p. 311. Cf. Hua XXVII (Europa: Crise e Renovação. A Crise da Hunanidade Europeia e a Europa), trad. de Pedro Alves. Lisboa: Centro de Filosofia da Universidade de Lisboa, 2006, pp. 119 e ss.

${ }^{6}$ Luís Cabral de Moncada, "Breve Esclarecimento de Algumas Teses de Filosofia Política, Moral e História"», p. 228. 
ideia será desenvolvida quando o jusfilósofo luso refere e conceito da consciência como intencionalidade. Igualmente, converge com a fenomenologia na ideia de história. Próximo das palavras husserlianas, "a história não está aí como um armazém", 7 considera que o devir histórico é dinâmico compreendendo-se como uma unidade completa de fins, convergências e divergências.

Pensar a história é pensar a consciência, ou seja, é descobrir não só que há tempo fora e para a consciência, mas que a própria consciência é tempo (consciência categoria-histórica). ${ }^{8}$ Seguindo esta linha de pensamento, anos mais tarde, relaciona história e filosofia num sentido que relembra as palavras de Husserl, "Não há qualquer dúvida de que temos de nos aprofundar em considerações históricas, se devemos poder compreender-nos como filósofos e compreender isso que em nós quer surgir como filosofia". ${ }^{9}$ Deste modo, a «situação histórica» é o âmago no qual os problemas nascem para a consciência de uma época, dotados de novas perspetivas e conexões vitais, "colhidos de uma nova experiência que lhes dão uma figuração especial e única". ${ }^{10}$ Logo, a história não é um aglomerado de vivências primárias segundo impulsos e inclinações habituais, mas, já, o resultado do sujeito que num movimento interno sobre si próprio se determina e escolhe submetendo "o conjunto da sua vida a uma vontade geral e refletida"." Por último, encontramos outra aproximação à fenomenologia dada na análise que faz sobre o ser e o dever-ser no domínio das ciências naturais e humanas. Opondo-se a António Sérgio, na sua visão monista da ciência, Moncada afirma que o dado não se restringe ao fenómeno espácio-temporal, mas abre-se para o campo dos valores, constituindo-se este como um domínio intermédio - domínio da Cultura - entre o ser e o dever-ser. Nas reflexões posteriores, retoma esta posição partindo do pensamento de Emil Lask e Max Scheler.

2. Das considerações estabelecidas concluímos que nos escritos da Polémica a presença da fenomenologia está embrionária. Com efeito, é no ensaio Valor e sentido da democracia que temos verdadeiramente o encontro com aquela corrente de pensamento através de Max Scheler e da sua obra Formalismo na ética e ética material.

\footnotetext{
${ }^{7}$ Hua VI, p. 532 .

${ }^{8} \mathrm{Vd}$. Luís Cabral de Moncada, "Ideal e Facto Sensível". Nação Portuguesa, tomo II, Série V, $2 .^{\circ}$ fasc., n. ${ }^{\circ}$, março de 1929 , p. 206. Cf. Hua VI, pp. 84 e ss.

${ }^{9}$ Hua, VI, trad. de Diogo Ferrer. Lisboa: Centro de Filosofia da Universidade de Lisboa, 2008, p. 531 .

${ }^{10}$ Luís Cabral de Moncada, “A Caminho de um Novo Direito Natural”. Estudos Gerais, vol. I, Série Universitária. Lisboa: Imprensa Nacional-Casa da Moeda, 2004, p. 142.

"Hua XXVII, p. 48.
} 
Assim vejamos: a primeira referência surge a propósito do sistema de valores do democratismo. À questão se os «valores da personalidade», na conceção personalista, são os mais elevados estando a eles subordinados os restantes valores da sociedade e da cultura objetiva, Moncada, demarca-se de todo o personalismo que foi compreendido a partir de uma razão meramente idealista e abstrata, herança do racionalismo iluminista. A sua crítica incide na sobrevalorização dos valores «formais», condicionantes e mais abstratos e uma desvalorização dos «materiais» considerando muitas vezes os valores «formais» como valores «materiais». Escreve: "Entre subordinar todos os valores da sociedade e da cultura aos valores da «personalidade» e subordinar todos os valores (inclusive os da «personalidade») aos da sociedade ou da cultura a escolha, visto tratar-se de «fins últimos», terá de renunciar a todo o carácter científico rigoroso, no sentido de demonstração fundada na «experiência indutiva». Todavia se tomarmos a palavra «experiência» no sentido lato de experiência «imanente», de experiência no sentido fenomenológico da palavra, abrangendo o a priori da intuição das «essências», então não será dificil achar também um fundamento «empírico» (lato sensu) para a nossa preferência dada aos valores da personalidade como os mais elevados [...] É numa «experiência» deste modo entendida que se funda a nossa preferência pelo «personalismo» como atitude inicial, a mesma sobre que os fenomenologistas fundam a sua ciência da moral, como, por exemplo, Max Scheler". ${ }^{12}$

Subscrevendo a crítica de Max Scheler à doutrina do racionalismo individualista do Iluminismo, segundo a qual, em traços largos, quanto mais se aproximam do plano da Razão mais os valores humanos e os sujeitos são iguais, e, inversamente, quanto mais ficam no plano inferior dos factos sensíveis tanto mais serão desiguais, o pensador português ensina que a autêntica natureza da personalidade requer a «espiritualidade pura», ou seja, uma individualização mais diferenciada dos sujeitos, pois aquilo que distingue os homens uns dos outros é a profundidade alcançada no desenvolvimento da sua personalidade. Esse desenvolvimento opera-se na passagem de uma vida segundo impulsos e inclinações habituais para um movimento de reflexão que o sujeito faz sobre si mesmo e o seu agir, tornando-se, próximo de Husserl, "o eu que se determina e se escolhe". ${ }^{13}$

Ainda neste texto, e apresentando afinidade com o pensamento fenomenológico, está a crítica elaborada à ideia de «unidade social». A «unidade social», como tem sido entendida, é o resultado da soma dos indivíduos racio-

12 Luís Cabral de Moncada, "Valor e Sentido da Democracia". Estudos de filosofia do direito e do Estado, vol. I. Lisboa: Imprensa Nacional-Casa da Moeda, 2004, nota 63, pp. 187-188.

${ }^{13}$ Hua XXVII (Europa: Crise e Renovação. A Crise da Humanidade Europeia e a Europa), trad. de Pedro Alves. Lisboa: Centro de Filosofia da Universidade de Lisboa, 2006, p. 48. 
nais que no decurso histórico têm como suporte das suas relações e, consequente sociedade, a ideia de contrato. Assim sendo, o «todo» constitui-se como uma rede abstrata de relações de usanças, convenções e contratos entre os sujeitos. Estes formam-se a partir do interesse individual dos sujeitos e do sentimento primário de desconfiança de todos para com todos, negando-se a autêntica solidariedade humana. Esta «unidade social» erigida na única possível recusa uma realidade moral superior, a possibilidade de um qualquer valor autónomo diferente do dos indivíduos e não reconhece que a personalidade metarracional do indivíduo apela, precisamente, para a existência desses valores. Neste contexto, Moncada retoma o pensamento fenomenológico na pergunta: "não se descobrirá na consciência da personalidade também algo (de que existe uma intuição direta, uma Wensenschau, no sentido fenomenológico, de Husserl ou Scheler), como o pressentimento de uma outra forma superior de «unidade social», correspondendo à ideia de um verdadeiro reino de amor e solidariedade entre os homens?" 14 No seguimento desta questão responde, próximo e concordante com Max Scheler, que a essência da personalidade humana não consiste exclusivamente na Razão, mas está na própria vida, na sua totalidade e em toda a extensão, o que conduz a afirmar que é no sentimento de uma "intuição emocional" dos valores absolutos, ou num $a$ priori do espírito que encontramos a síntese superior do indivíduo e da sociedade, ou seja, a autêntica «unidade social».

Três anos mais tarde, no «Prefácio» à tradução portuguesa de Filosofia do direito, de Gustav Radbruch, traçando a matriz do seu pensamento filiada na escola de Baden, Moncada faz nova referência à fenomenologia a partir de Lask, inspirador do pensamento de Radbruch, o qual num contexto fenomenológico procurou ultrapassar o kantismo e o neokantismo. "É, com Nicolai Hartmann, um dos representantes da corrente filosófica que procura uma aproximação entre a fenomenologia - filosofia de tendências intuicionistas e realistas por excelência - e o criticismo". ${ }^{15}$ Tendo em conta a visão kantiana e neokantiana e, sobretudo seguindo a perspetiva de Rickert, Lask dirige para o campo da filosofia do direito a ideia de que o domínio da Cultura é intermédio entre o da Natureza e o dos Valores.

Acolhendo a visão segundo a qual os valores têm validade independente da realidade constituindo-se como uma sua «significação», numa perspetiva fenomenologista, sustenta que os valores são como essências objetivas, apreensíveis por uma «intuição essencial» (Wesenschau). O «mundo de significações» fornecido por essa «intuição essencial» é o único objeto da ciência

${ }^{14}$ Luis Cabral de Moncada, "Valor e Sentido da Democracia", cit., p. 199.

${ }^{15}$ Ob. cit. 
jurídica, a qual se funda sobre a «teoria do conhecimento». Assim, o direito será compreendido através da relação consciência-mundo reconhecendo-se a consciência como intencionalidade. Deste modo, não só rejeita que o direito esteja fundamentado na psicologia ou na sociologia, mas também esclarece aquilo que é verdadeiramente jurídico do que é psicológico, histórico, filosófico e sociológico. Considerando que o Direito constitui uma parte da «ciência da cultura» (Kulturwissenschaft), e, convergindo neste ponto com a conceção fenomenológica, Lask, por um lado, mostra que o Direito ao revelar-se nos diversos sistemas jurídicos só é possível pela atividade intencional da consciência que descreve "o ser do Direito como uma estrutura de essência ou sentidos que caracterizam originariamente esse objeto", ${ }^{16}$ por outro lado, defende que o princípio da formação de conceitos jurídicos será compreendido segundo o sentido teleológico das ciências culturais, sobretudo ideográficas.

3. Estas ideias que apresentámos foram retomadas, desenvolvidas e esclarecidas nos diversos textos que Luís Cabral de Moncada escreveu posteriormente.

A primeira observação que se nos oferece fazer concerne ao conceito de filosofia. Seguindo uma orientação fenomenológica, considera o pensador português que a filosofia começa com os problemas da possibilidade do conhecimento, pois saber o que é qualquer coisa é perguntar, antes de mais, pelo saber do $s a b e r,{ }^{17}$ daí a primazia dada à gnosiologia e à epistemologia. No entanto, como adverte, ao procurar saber as condições da possibilidade e da validade do conhecimento de uma qualquer realidade, estamos já, simultaneamente, num plano ontológico. Deste modo, estamos face a uma ontognosiologia. A segunda observação prende-se com o conceito de filosofia do direito. Esta é interrogação sobre o conhecimento do mundo jurídico. Mas num primeiro momento este mundo, que está aí, revelando-se pela atitude espiritual natural, não é ainda conhecimento, apesar de o caracterizar certa referencialidade e intencionalidade essenciais com o tipo de questões a que pretende responder. O saber filosófico sem descurar as preocupações empíricas e práticas procura um "denominador comum racional, no plano da mais alta problemática relativa ao saber, ao ser, ao valor e ao absoluto do direito". ${ }^{18}$

${ }^{16}$ Aquiles Cortes Guimarães, "Edmundo Husserl e o Fundamento do Direito". Fenomenologia e Direito, Cadernos da Escola de Magistratura Regional Federal, 2(1), EMARF, p.76.

17 Luís Cabral de Moncada, "Sobre Epistemologia Jurídica". Estudos de Filosofia do Direito e do Estado, vol. II, Série Universitária. Lisboa: Imprensa Nacional-Casa da Moeda, 2004, p. 86. Cf. Edmund Husserl, A Ideia de Fenomenologia, trad. de Artur Morão. Lisboa: Edições 70, pp. 21 e ss. (Textos Filosóficos).

${ }^{18}$ Luís Cabral de Moncada, "Sobre Epistemologia Jurídica", cit., p. 85. 
Em termos de matéria do conhecimento, as reflexões de Moncada começam pela epistemologia fenomenológica descritiva. Por ela, se intui e descreve as essências formais e materiais do pensar, as suas estruturas e intencionalidades. A filosofia do direito será, pois, inspirada pelo método fenomenológico, através do qual o «jurídico» e o «político» se manifestam no direito e no Estado, revelando, igualmente, as valorações que presidem a esses domínios. $\mathrm{Na}$ dimensão ontológica e axiológica, revela a fenomenologia que todo o pensamento tende para um objeto, pelo que a consciência é sempre consciência de si e de algo mais que a transcende. ${ }^{19}$ Neste contexto se funda a diferença entre «ôntico» e «ontológico», sendo o primeiro um ontológico fraco, a significar esta expressão que nele está o ser na estrutura particular do objeto tal como este nos é dado, por outras palavras, o ser da atitude espiritual natural; o segundo é um ontológico forte, aspirando e manifestando significação metafisica, permitindo uma teoria do conhecimento capaz de um "autêntico realismo epistemológico dum ser extramental e de consistência ultra-empírica".

Reconhece Moncada que só o método fenomenológico possibilita descobrir essas orientações e as hierarquias ônticas que se estabelecem entre elas, esclarecendo "relações de meios e fins, de condicionante e condicionado, a que não é lícito negar a natureza de alguma coisa que é assim mesmo como é, transubjetivamente valendo para lá do capricho e da vontade dos homens". ${ }^{20}$ A filosofia do direito, segundo esta orientação fenomenológica, é o ato de descrever as essências ou sentidos desse objeto que chamamos direito e se apresenta de forma única, típica, circunscrito no mare magnum dos dados da experiência das coisas sociais, sem se confundir com outros objetos dessa experiência, por isso requer uma metodologia e ontologia próprias, das quais a fenomenologia aparece como o primeiro momento.

4. O conhecimento do direito pressupõe o conceito de direito como sendo a priori, condição de possibilidade da "experiência" jurídica e constitutivo do direito-positivo. Este domínio da jurisprudência implica certos conteúdos intelectuais tidos como reais, porque são dados pela experiência (objeto) e pensados pelo homem (sujeito). Tais conteúdos são os "conceitos jurídicos", ou as categorias e leis lógicas que constituem o pensamento jurídico, sendo já uma resposta às interrogações, "que é, e onde está, e como funciona, o fator ou pólo subjetivo na elaboração do conhecimento científico do direito?

${ }^{19}$ Cf. Garcia Domingues, Da Essência, da Existência e da Valência. Investigações sobre as Raizes Metafisicas do Pensamento e as Perspetivas Transcendentais do Ser. Separata da revista da Faculdade de Letras, tomo VII, Lisboa, 1939, pp. 53 e ss.

${ }^{20}$ Luís Cabral de Moncada, "Sobre Epistemologia Jurídica", op. cit., p. 89. 
Como opera aqui o sujeito na elaboração do seu objeto?" 21 Retomando a linguagem da fenomenologia moderna, uma análise gnosiológica dos conceitos pressupõe a noção de intenção. A intenção de um conceito é aquilo para que esse conceito tende, traduz o que o conceito "quer dizer na sua" linguagem implícita como facto da consciência que tende para um objeto, sem o que deixará de ter sentido.

Diferenciando os conceitos em reprodutivos ou objetivos e constitutivos originários, Moncada considera serem estes últimos que se reportam ao direito. E a sua intenção afirma-se pelas vivências primordiais de valores que naturalmente nascem da própria consciência, orientando-se para o campo da ação e do dever-ser. Deste modo, exprimem todas as criações humanas ou, se quisermos, o próprio ser, na medida em que aquelas criações são o fruto da ação deste, daí decorrendo o seu carácter de imanência. Pressupõem relações de dinamismo vital ou intelectual, sendo tributários de valores e, daí, serem constitutivos, pois dão-nos "a chave de todas as nossas criações do espírito, que somos nós próprios. Como que exprimem e projetam para fora de nós alguma coisa que está já em nós. E por isso lhe chamamos objetivos e originários". ${ }^{22}$ Estes conceitos constitutivos são originários e também objetivos, referindo-se, em si mesmos, a certas específicas objetividades que dão origem à cultura.

5. Inspirando-se na análise kantiana da estrutura da experiência e tendo presente a ontologia formal de Husserl, Luís Cabral de Moncada considera que todos os conceitos «compreendem» outros pensamentos, que, independentes do ato psicológico, se apresentam como objetividades e estruturas específicas, apreendendo-se segundo uma forma especial de intuição (eidética) ou intuição essencial. Por conseguinte, partindo do conceito de direito ou de experiência jurídica como a priori, originário, constitutivo e objetivo a primeira ideia que aquele conceito compreende é a de dever-ser. O direito faz parte do mundo do dever-ser, o qual constitui no pensamento do direito um seu objeto intencional, pois dá-se imediatamente à consciência: é intuitivo, apodítico, não necessita de demonstração. Próximo do neokantismo da escola de Baden, Cabral de Moncada diferencia entre o mundo do ser, da representação, da coisa empiricamente observada, ${ }^{23}$ e o mundo do dever-ser, que se reporta a valores, intenções e preferências.

${ }^{21}$ Ibid., p. 46.

${ }^{22}$ Ibid., p. 50.

${ }^{23} \mathrm{O}$ mundo do ser é o mundo das ciências naturais, cujo desiderato é descobrir as relações constantes e universais entre os fenómenos e formular as leis que as exprimem, tornando o conhecimento acerca da realidade previsivel e manipulável pelo homem. 
Esta distinção entre estes domínios deve estar na base de toda a reflexão filosófica e estas realidades são ideias, não estão, ainda, definidas. Estabelecem dois domínios de máxima «extensão» e de «mínima compreensão». Olhando, somente, do ponto de vista do pensamento individualizador e coisificador, atendendo, apenas, às representações de fins práticos e valiosos tudo para o pensamento são «deveres-seres», apelos e valores. Na perspetiva das objetivações teóricas e prescindindo da substancialização metafísica, tudo são seres e coisas.

Se esta diferença ainda não esclarece o conceito de direito, não deixa de conferir a priori a ideia mais geral que ele engloba, o dever-ser, e a essência significativa que o determina, ser intuitivo, não necessitar de demonstração. A esta intuição do dever-ser correspondem as ideias de valores e de normas. Dever-ser, valor e norma dão-se em correlação. O valor é um fenómeno primário concreto da consciência que se capta por via intuitiva, antes que, sobre ele, se exerce qualquer intelectualização; a norma já manifesta uma construção generalizante, fruto da intersubjetividade das consciências, que implica viver em comum. É uma representação secundária, de natureza intelectual e dialética, dos valores. O dever-ser é a síntese da norma e do valor num plano intelectual mais abstrato e generalizante. Só em relação à norma e ao valor adquire sentido, pois sem a ideia de valor nenhum dever-ser teria sentido para a nossa consciência pessoal, do mesmo modo que sem a ideia de norma nenhum valor ganharia significado e eficácia na vida comunitária. Tanto o valor como a norma são "apelos dum dever-ser que os engloba numa mesma suprema e fundamental dimensão do espírito". ${ }^{24} \mathrm{O}$ dever-ser é, pois, o pensamento-síntese de valores e normas.

6. Avancemos mais na consideração do conteúdo do conceito de direito, não esquecendo que os pensamentos contêm em si outros pensamentos, que nos conduzem a significações irredutíveis, àquilo que chamamos «categorias» do pensamento no seu processo de ideação. Ora, precisamente, uma dessas categorias é a liberdade.

Não é possível pensar os valores, o dever-ser e as normas, o seu conteúdo noemático, fenomenologicamente, se não tivermos a ideia de liberdade. $\mathrm{Na}$ linguagem do autor, "se penso que devo, não é admissível deixar de pensar que posso também e que sou livre. É uma necessidade para o pensamento de dever o pensamento de liberdade. E esta relação interna constitui [...] objetividade necessária, de natureza não psicológica, mas mais do que lógica: noe-

${ }^{24}$ Luís Cabral de Moncada, Filosofia do Direito e do Estado, ed. cit., vol. П, p. 37. 
mática e fenomenológica". ${ }^{25} \mathrm{Na}$ verdade, a liberdade concerne a um conteúdo da consciência, uma vivência, um ego que se pensa a si próprio em termos atuais ou potenciais, com o poder ou a possibilidade de eleger fins pré-determinados. ${ }^{26}$ Assim surge como mostração ou descrição dum conteúdo da consciência, no fluxo puro do vivido, que está já implícito no conceito de direito. Daí decorrendo que não se pode pensar a essência-direito sem pensar a essência-liberdade. E, advirta-se, a nossa e a dos outros.

A ideia de liberdade postula a de personalidade, na medida em que ser pessoa implica a capacidade de deliberar e escolher, a qual por sua vez só é possível pela liberdade. Liberdade e personalidade são o mesmo. $\mathrm{Na}$ expressão de Moncada, seguindo o método da intuição, a pessoa será "o centro de atos livres e de autodeterminações voluntárias, para a qual as normas, os valores e o dever-ser existem". ${ }^{27}$

Mas no isolamento ninguém é, nem realiza o seu dever-ser. Toda a nossa personalidade se constitui no dar ou recusar de braços; o Eu pressupõe o Outro; o Ego o Alter Ego, por isso, "o verdadeiro lugar de génese da intersubjetividade será, assim, a vontade de constituição de comunidade" ${ }^{28}$ e só neste sentido, toda a relação com o outro é de colaboração e convivência, e, acrescentamos nós, também pode ser de confronto. Nascem dessa relação os pensamentos intuitivos de relação, relações, parte e todo, um e muitos. Estas noções não são conceitos matemáticos nem lógicos, mas referem-se à ideia de personalidade. Daqui decorre que o direito é pensado não no sentido de uma mera coexistência de personalidades, mas na via de uma convivência de fins. Esta natureza essencial-relacional está presente no conceito de direito e antes de qualquer experiência jurídica. Nesta teia de pensamentos, a convivência e a colaboração reclamam com igual importância as ideias de ordem e justiça.

A ordem, para exercer a sua função conciliatória, pressupõe no seu íntimo o ideal de justiça. Como conceito a priori do direito, a justiça é compreendida em termos formais e não segundo valores de conteúdo. A ideia de justiça distingue-se da justiça como valor. A primeira é a priori e concerne à vivência transcendental necessária e absoluta; a segunda realiza-se no domínio concreto, concretiza-se como uma vivência existencial e histórica. A ideia de justiça não se confunde, por isso, com a justiça em sentido ético ou político, por isso, entender a justiça na sua essência-formal, é compreendê-la como a ideia

${ }^{25}$ Ibid., p. 55.

${ }^{26}$ Ibid., p. 56

${ }^{27}$ Ibid., p. 57.

${ }^{28}$ Pedro Alves, Intersubjetividade e Comunicação. Uma Abordagem Fenomenológica. Lisboa: Centro de Filosofia da Universidade de Lisboa, 2009, p. 97. 
máxima do direito, ou seja, a justiça é a ordem perfeita, que se manifesta como proporção e igualdade, significando que "será justa, [...] formalmente, toda a ordem que assentar na atribuição igual a cada um - no seu ter ou no seu dever fazer - daquilo que especificamente lhe pertence [... $]^{\prime 29}$

Todas estas considerações, de ordem geral, foram-nos fornecidas por meio da análise fenomenológica das essências formais, das intencionalidades dos atos. Contudo, estas essências formais ou noéticas requerem as essências materiais ou hiléticas, que possibilitam, como adverte o professor de Coimbra, "depois, dentro da região, determinar mais concretamente, como a espécie dentro do género, o «objeto» específico do que se trata". ${ }^{30}$

7. Todavia, compreender o conceito de direito não é, ainda, conhecimento do direito. Partindo desta afirmação Moncada refere quatro momentos de conhecimento jurídico.

O primeiro, corresponde ao conhecimento espontâneo ou vulgar do direito e caracteriza-se por os seus juízos serem "juízos de existência" objetivados, entre outros, nos tribunais, códigos e juízos. Delimitam o que é e não é jurídico na vida social. Apontam para valores, embora ainda não sejam juízos de valor, são significativos de uma certa realidade, a jurídica, conferindo-lhe um "primeiro" sentido (juízos de sentido). O segundo é constituído pelo conhecimento jurídico do direito e neste domínio os juízos já são de valor e patenteiam atitudes e vontades dos sujeitos perante a realidade, manifestando as suas preferências e rejeições, aprovações e desaprovações. Nestes juízos de valor manifesta-se uma relação de dever-ser entre, por um lado, um certo valor ou critério de valor e um comportamento da vontade humana e, por outro lado, uma relação de concordância ou não, de aprovação ou não, entre um ato humano já realizado ou a realizar e esse mesmo valor ou critério de valor.

Escreve, "Não há só o «valor» e o «valor em abstrato»; há também os «valores» em concreto; por assim dizer com corpo e alma, com vida, sangue e nervos. Está aí o seu quid de insofismável realidade não física, mas histórica e cultural: a sua característica: objetividade e positividade". ${ }^{31}$ Apresentam-se como juízos imperativos-normativos e juízos de valoração, pressupondo os segundos sempre os primeiros. A linguagem do direito é expressiva de tais juízos: alguém em certas condições deve proceder de certo modo; alguém

${ }^{29}$ Luís Cabral de Moncada, Filosofia do Direito e do Estado, ed. cit., vol. II, p. 61. No conceito de direito o que é particular na ideia de justiça é a ideia de igualdade ou proporcionalidade perfeita.

${ }^{30}$ Luís Cabral de Moncada, "O Direito como Objeto de Conhecimento", cit., p. 116.

${ }^{31}$ Luís Cabral de Moncada, "Sobre Epistemologia Jurídica”, cit., p. 69. 
deve deixar que outrem faça isto ou aquilo; tal ato é lícito ou ilícito, e assim por diante.

É no contexto da compreensão ontológico-fenomenológica que Luís Cabral de Moncada medita sobre o sentido axiológico do direito, definindo os valores como "objetos ideais". Ontologicamente, os valores são seres com objetividade e efetividade, apesar de não serem reais. Estão acima do espaço $e$ do tempo, mas não são construções imagéticas e fictícias do homem. Deste modo, os valores como que se vertem, encarnam na realidade sensível ao serem concretizados sob a forma de fins, que o homem se propõe atingir, ou como qualidades que se atribuem às coisas. Se, por um lado, são relativos, pois só pelo homem são; por outro, a tendência à universalidade e à objetividade confere-lhes um sentido absoluto, se atendermos a que, já na sua concretização, já na sua intenção são portadores de um certo quid de sentido e validade supratemporais.

$\mathrm{O}$ terceiro momento é o conhecimento científico do direito: o direito situa-se no domínio das chamadas ciências culturais e nesse sentido visa compreender os valores espirituais objetivados. Estes, apreendidos como algo individual, único, captam-se, às vezes, num ápice, como visão súbita de sentido de complexas significações tornando este singular em ciência ideográfica. Não obstante, não há ciência do individual, sendo que a ciência do direito, que se considera ideográfica, porque busca a apreensão do único e o "individual-concreto", passa a nomotética, pois, como todas as ciências, procura o conceitual, o universal, o lógico e a dialética, mediante a sua atividade de concetualização.

Tudo isso implica um processo, assim, na conceptualização, um primeiro grupo de conceitos refere-se às categorias fundamentais, a priori, a título de exemplo, temos a norma ou lei; sujeito de direito; direitos objetivos e direitos subjetivos; ordem e desordem; delito e pena; ato jurídico; lícito e ilícito. Esta rede de conceitos que antecede toda a experiência, é condição de possibilidade, não só do pensar juridicamente, mas também, condicionam a experiência para, posteriormente, elaborar a ciência jurídica. Um segundo grupo de conceitos são os empíricos. Nascem da experiência da vida jurídica de cada época e país, caracterizando a vida social num determinado contexto histórico. Seguidamente temos a construção, que é a passagem do "dado ao construído", isto é, refere-se à logificação dos conceitos, à sua organização, estrutura, hierarquização, universalidade e abstração. Partindo dos princípios, valores, juízos, raciocínios, factos e finalidades, criam-se os conceitos adequados à realidade jurídica. Este momento, já científico, complementa-se com a sistematização.

A sistematização é o grau mais elevado do processo científico do direito. Acaba por ser a construção da construção, mais perto da unidade, mais geral 
e abstrata. Escreve o pensador conimbricense: “O jurista edifica desta arte - dir-se-ia - verdadeiras pirâmides de conceitos abstratos. Procura aí depois subordinar os conceitos menos gerais aos mais gerais, até chegar aos mais altos dos institutos e instituições e classificações destas, e arruma tudo isto dentro de quadros rígidos de pensamento que serão para ele, enquanto cientista, tanto mais verdadeiros e úteis quanto mais completos e fechados forem de modo a caber lá dentro toda a realidade com que se defronta". 32

Neste processo, através da indução e da dedução, o jurista tanto vai do caso particular para o geral da lei, como faz o caminho inverso. A linguagem por excelência é a lógica que pode ser pura, formal, a priori e abstrata, cuja finalidade é a pura inteligibilidade e compreensão dos conceitos, como pode ser pragmática e programática, tendencial, teleológica e a posteriori em vista do fim prático, isto é, da aplicação do direito à vida social. A técnica jurídica consiste já na aplicação do direito à vida, e também no posterior desenvolvimento do direito para além desses casos e situações. Recorde-se, como exemplo de técnica jurídica, a sentença onde o juiz subsume o caso particular sob o domínio de um ou mais preceitos legais aplicáveis, fazendo uma adaptação do geral e essencial ao individual e existencial.

$\mathrm{Na}$ verdade, próximo da interpretação fenomenológica, revelando o direito um sentido cultural, os "sentidos" e "significações" expressos nas leis e que o intérprete tenta captar têm uma objetividade própria. Daí a interpretação objetivista que compreende ou vai à procura de um "pensamento pensado", objetivado na lei. Portanto, a mens legis que apreende ou interpreta os pensamentos pensados opõe-se à mens legislatoris, ao puro ato psicológico do legislador empírico.

Finalmente, o quarto momento vem a ser o do conhecimento filosófico do direito: no que importa insistir, para não cairmos em repetições, basta-nos lembrar que a filosofia o direito interroga o direito, já não como técnica ou ciência, mas como fundamento, procura nele o que permitiu a sua criação, o que o legitima, o que o valida e, nesse esforço de o pensar na sua dimensão mais radical e profunda, intenta alcançar, mediante um esforço crítico, reflexivo e especulativo, o seu ser e o seu valor.

8. Porém, não fica tudo dito: qual a região a que pertence o direito-positivo? A resposta não é difícil. Próximo da teoria dos objetos, e na senda da ontologia pluralista do real, a natureza ôntica do direito é ser "espírito objetivo", reunindo este, simultaneamente, os seres ideais, reais, existentes não-sensíveis e existentes sensíveis.

${ }^{32}$ Luís Cabral de Moncada, Filosofia do Direito e do Estado, ed. cit., vol. II, p. 73. 
O "espírito objetivo" é a ideia de direito entendida como realidade histórica concreta: é a ideia de direito constituída por valores, normas, critérios, preferências, interesses, finalidades, em suma, é o direito positivo e cultural. É numa orientação fenomenológica que Moncada compreende a cultura. Consideremo-la nas seguintes palavras: "O ego socializado num nós comunitário, objetivando-se nas trocas comunicativas imediatas ou mediatizadas é impensável sem um fundo de assunções partilhadas [...] O conjunto dessa assunções dá a base para o conceito fenomenológico de cultura [...]" e um "mundo cultural é um tecido de idealidades que só na medida em que são interiorizadas podem ser apreendidas e compreendidas enquanto tais". ${ }^{33} \mathrm{Nesse}$ sentido, como criação cultural o direito nasce da liberdade humana, sem que antes o encontremos noematicamente como conceito a priori da consciência.

Como ideia, o direito constitui-se como um conjunto de princípios válidos em si mesmos, como o princípio da justiça, da igualdade, da boa-fé, da responsabilidade. Reconhece Moncada que estes princípios, embora válidos por si mesmos, necessitam de ser realizados, o que só é possível quando se consubstanciam na norma, de tal modo que, de simples ideia o direito torna-se aí realidade concreta. E se o direito positivo é o "espírito objetivo", se é o direito traduzido nas normas, então, a maior parte das normas tem o seu fundamento no direito como Valor.

A problemática é a seguinte: "se é lícito saltar da ordem ontológico-fenomenológica para a ordem ontológico-metafisica, no sentido clássico ou no de realismo crítico contemporâneo?". ${ }^{34}$

Se não é possível demonstrar, segundo os métodos lógico-discursivos, a existência de um mundo exterior, transcendente ao homem, e se a pura contemplação dos valores também não nos conduz a ele, todavia, escreve o pensador conimbricense, na senda de Hessen, que "alguma coisa afinal tem realidade e vale, ainda para além do limitado horizonte da existência do indivíduo humano". ${ }^{35}$

9. Uma última observação a fazer da leitura atenta dos textos referidos é a que concerne à Justiça e ao Direito Natural.

Ao atendermos a estes elementos estamos a apreciar o direito na sua perspetiva ideal ou como dever-ser e não como direito que é. Estamos, se bem recordamos, a reencontrar a categoria ôntica do sentido ou conteúdo axiológico do direito, daí emergindo a pergunta: "será possível determinar e cons-

${ }^{33}$ Pedro Alves, Intersubjetividade e Comunicação. Uma Abordagem Fenomenológica, ed. cit., p. 104.

${ }^{34}$ Luís Cabral de Moncada, Filosofia do Direito e do Estado, vol. II, p. 285.

${ }^{35}$ Ibid., pp. 284-285. 
truir por meios racionais um direito que deva ser?". ${ }^{36} \mathrm{Na}$ verdade, inquirimos se o direito tem, em si próprio, o seu fundamento ou se necessita de fundar-se em algo superior e diferente de si, que constituiria a sua razão de ser e de valer.

Recusando as teses do jus naturalismo essencialista e racionalista, ou as que negam o direito natural, para o pensador conimbricense, o único direito natural admissível é um direito natural de conteúdo variável. Para melhor compreendermos esta tese devemos começar por distinguir, na ideia de direito, o que é o valor formal e o que são os valores de conteúdo. E nessa distinção descobrimos a justiça como sendo o valor formal mais elevado. Com efeito, a justiça é a mais elevada realização do direito. Admitindo que não há, propriamente, uma justiça, mas várias justiças, entre outras, uma justiça capitalista e uma comunista, uma democrática e uma aristocrática, reconhece Moncada que a justiça se apresenta como um valor objetivo, universal, válido em si mesmo e formal naquelas três ideias, suum cuique tribuere, pacta sunt servanda e neminem laedere.

A justiça, enquanto conceito a priori, é proporção e igualdade. É justa toda a ordem que fizer uma igual distribuição por cada um segundo o que lhe pertence e consoante os seus méritos; é justa a ordem em que cada um realize as tarefas que lhe são próprias no interior da comunidade. Assim a justiça ordena o individual com o coletivo, concilia os fins próprios de cada um com os fins da vida social. Na procura de equilibrar os fins individuais e coletivos, a justiça funda-se no valor da personalidade humana, a qual se realiza através da liberdade. A "personalidade é - embora abstratamente, é certo - a condição e a fonte de todos os valores, o órgão que nos dá aqui a visão da luz". ${ }^{37}$ E a liberdade, entende-a o mestre coimbrão à maneira kantiana, ou seja, não se preocupa com o problema do livre-arbítrio ou do determinismo, mas o seu objetivo é mostrar que sem ela jamais o valor, a norma e o dever-ser se podiam manifestar, como já foi referido. Naturalmente que a liberdade é compreendida como sendo histórica, dinâmica e em situação: "A liberdade é uma mostração ou descrição dum conteúdo da consciência, no fluxo puro do vivido, que vai já implicitamente incorporado no conceito de direito". ${ }^{38}$ Esta relação intima entre o pensamento de dever-ser e o de liberdade, o "constitui também para nós uma objetividade necessária, de natureza não psicológica, mas mais do que lógica: noemática e fenomenológica". ${ }^{39}$ Nesta perspetiva, podemos

\footnotetext{
${ }^{36}$ Ibid., p. 288.

${ }^{37}$ Ibid., p. 290.

${ }^{38}$ Luís Cabral de Moncada, "Sobre Epistemologia Jurídica", cit., p. 56 e ainda, a liberdade como o "sentimento dum poder próprio de determinação ou de autodeterminação em vista de certos fins previamente eleitos".
}

${ }^{39}$ Ibid., pp. 40 e ss. 
afirmar que a justiça nos conduz a absolutizar como preceito valioso não só a personalidade humana, mas também a lei natural, naqueles três princípios que foram enunciados e nos restantes valores espirituais.

Do exposto deparamos com a interrogação feita por Moncada no texto O Problema do Direito Natural no Pensamento Contemporâneo: "qual a estrutura desses objetos a que chamamos espirituais, e quais as leis a que teremos de obedecer para os ajudarmos a realizarem-se - e, entre eles, acima de todos, os da justiça e do Bem no seio das sociedades humanas?". ${ }^{40}$ Esta interrogação coloca a questão de como articular os valores no seu sentido universal e imutável com a verificação de por um lado, a natureza humana ser mutável e, por outro, de que à realização dos valores não serem indiferentes e alheios os condicionalismos socioculturais.

Convergindo com o neokantismo e na senda de Stammler, advoga uma conceção de direito natural segundo a qual se oferecem à consciência, a priori, determinados ideais éticos, certos princípios morais de valor universal, bem como existem e existiram também sempre no espírito do homem, em todos os tempos e lugares, uma ideia e um sentimento inatos de justiça. Assim entendidos, estes princípios ou valores, por si sós, não fornecem conteúdo para a estrutura da vida intersubjetiva, mas patenteiam-se segundo determinados ideais que se manifestam como "uma lei natural, de tendências profundas que pode ser reflexo de uma inteligência divina, ou de uma harmonia pré-estabelecida, ou do fieri de uma Ideia ou ainda da racionalidade do existente dinâmico: - metafisicamente, tudo isto se equivale". "Deste modo, a Metafisica será o ponto de chegada e não o ponto de partida, pois é a vida que determina, no direito e no direito natural, a matéria do seu conteúdo.

Ao incidirem sobre as múltiplas circunstâncias da vida social, os princípios éticos formais, como o pacta sunt servanda, o neminem laedere e o suum cuique tribuere, sendo mais formais do que materiais, originam tipos e sistemas de ideais distintos, porém, mais concretos de instituições a que se podem chamar outros tantos "direitos naturais". ${ }^{42}$

${ }^{40}$ Luís Cabral de Moncada, "O Problema do Direito Natural no Pensamento Contemporâneo". Estudos de Filosofia do Direito e do Estado, ed. cit., vol. II., p. 160.

${ }^{41}$ Ibid., p. 37.

${ }^{42}$ Nas palavras de Moncada: "Tal direito é como que o feixe das múltiplas projeções e reflexos derivados por uma luz única que de repente incidisse sobre a matéria de um conjunto de situações históricas iluminando-a diversamente. É o tipo ideal, paradigmático, do historicamente dado, depois de bafejado pelo sopro de alguns desses valores éticos absolutos e universais". 
10. Concluímos este nosso percurso sublinhando que Luís Cabral de Moncada foi o introdutor da Fenomenologia no direito em Portugal, ainda que se encontrem estudos de Garcia Domingues, Da Essência, da Existência e da Valência. Investigações sobre as Raizes Metafisicas do Pensamento e as Perspetivas Transcendentais do Ser (1939), texto onde revela conhecer autores como Husserl, Max Scheler e Nicolai Hartmann, de Franz-Paul de Almeida Langhans, a Conceção Fenomenológica do Direito (1941), e de António José Brandão, O Direito. Ensaio de Ontologia Jurídica (1942). Porém, embora estes textos façam breves referências à fenomenologia foi, de facto, Cabral de Moncada que refletiu de forma sistemática, consistente e séria, esta ligação entre a fenomenologia e a experiência jurídica.

\begin{abstract}
In this paper, I stress the importance of Luis Cabral de Moncada for the resettlement of the Philosophy of Law in the Portuguese university. I focus my attention on the overthrown of Positivism, and, as a consequence, on the reintroducing of axiological and ethical issues in the foundations of positive law. In so doing, I consider the relevance Phenomenology had for Moncada's theory of law, namely the theory of eidetic insight, and, particularly, the phenomenology of values. Moncada's appropriation of some phenomenological themes and concepts was developed in a close contact with Husserl, Scheler, and Nicolai Hartmann.
\end{abstract}

